\title{
Design and Prototyping of Electronic Load Controller for Pico Hydropower System
}

\author{
Supriyanto Praptodiyono ${ }^{1}$, Hari Maghfiroh ${ }^{2}$, Muhammad Nizam ${ }^{2}$, Chico Hermanu ${ }^{2}$, Arif Wibowo ${ }^{2}$ \\ ${ }^{1}$ Department of Electrical Engineering, Universitas Sultan Ageng Tirtayasa (UNTIRTA), Cilegon, Indonesia \\ ${ }^{2}$ Department of Electrical Engineering, Universitas Sebelas Maret, Surakarta Indonesia
}

\begin{tabular}{l} 
ARTICLE INFO \\
\hline Article history: \\
Received November 19, 2021 \\
Revised Desember 04, 2021 \\
Accepted Desember 24, 2021 \\
\hline
\end{tabular}

Keywords:

ELC;

Pico hydro;

Hydropower;

Control;

Frequency

\begin{abstract}
A hydroelectric power plant is an electrical energy generator that utilizes water energy to drive a water turbine coupled to a generator. The main problem in hydroelectric power plants is the frequency and voltage fluctuations in the generator due to fluctuations in consumer loads. The purpose of this research is to make a prototype of the Electronic Load Controller (ELC) system at the Pico Hydropower Plant. The main part of ELC is the frequency sensor and gating system. The first part is made by a Zero Crossing Detector, which detects the generator frequency. The gating system was developed with TRIAC. The method used is the addition of a complement load which is controlled by delaying the TRIAC. Load control is intended to maintain the stability of the electrical energy produced by the generator. The PID algorithm is used in frequency control. The results of the frequency sensor accuracy test are $99.78 \%$, and the precision is $99.99 \%$. The ELC system can adjust the frequency automatically by setting the firing delay on the TRIAC to distribute unused power by consumer loads to complementary loads so that the load used remains stable. The ELC is tested with increasing and decreasing load. The proposed ELC gives a stable frequency at $50 \mathrm{~Hz}$. Whereas at the first test, the mean voltage is $183 \mathrm{~V}$, and in the second test is $182.17 \mathrm{~V}$.
\end{abstract}

This work is licensed under a Creative Commons Attribution-Share Alike 4.0

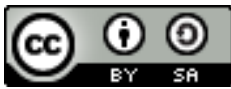

\section{Corresponding Author:}

Hari Maghfiroh, Department of Electrical Engineering, Universitas Sebelas Maret, Surakarta, Indonesia Email: hari.maghfiroh@staff.uns.ac.id

\section{INTRODUCTION}

Indonesia is an archipelagic country. There are many islands, some of the remote areas are not electrified yet. Since the difficulty of the location to the area so that it cannot be reached by The State Electricity Company (PLN) electricity. Whereas, according to [1][2], around 36\% population in Asia are living without electricity. One of the solutions to solve this problem is to utilize renewable energy in nature. Non-renewable electricity resources will run out, so water energy can be used as an alternative that can be used as a substitute for nonrenewable energy. Electrical power from water can be utilized with potential energy or kinetic energy produced by the water itself.

A hydroelectric power plant or hydropower is an electrical energy generator that utilizes water energy to drive a water turbine coupled to a generator. Hydropower is the most extensively used of renewable power, with around $19 \%$ of global electricity [3]. Based on the amount of electric power generated, there is a so-called pico-hydro power plant capable of producing a maximum output of up to five kilowatts [4]. Pico hydropower is simple, flexible, and inexpensive; hence, it is easy to install, work, and manipulate [5]. Pico hydro is very useful in the small remote community since it is low cost and solves the problem of transmission distance from power plant [6]. Therefore, according to [7][8], pico hydro is the best alternative for electricity production in remote and rural areas.

The main problem in hydroelectric power plants is the frequency and voltage fluctuations in the generator due to fluctuations in consumer loads. Controlling the voltage and frequency of the generator can be done by 
maintaining an active power balance between generator power and consumer load power [9]. Control of frequency and active power is called load frequency control (LFC) [10]. The LFC is intended to maintain the power balance in the system to ensure the frequency variation is within a specified range [11][12]. Electronic Load Controller (ELC) is the device used to do LFC to solve the problem of frequency fluctuation [13].

In order to obtain a constant generator frequency, regulation is carried out on ballast load with several techniques such as phase angle regulation and binary load [14]. It is hoped that by using a regulation system, the system can work optimally in frequency control. According to [15], there are four group of LFC control which are: (i) classical control such as PID [16][17]; (ii) modern control including optimal control, sliding mode control, distributed model predictive control [18]; (iii) intelligent control such as fuzzy-logic [19][20], and artificial neural network [21]; (iv) soft-computing based approach for controller parameter tuning for instance using Genetic Algorithm (GA) [22], Particle Swarn Optimization (PSO) [23][24] and Differential Evolution [25]. In this research, PID is used since, according to [9], it is most popular in LFC, and it has a simple structure and robustness.

The contribution of this research is the proposed simple ELC for the Pico hydropower system, which is suitable for installation in a remote area that requires easy to maintain and low-cost controllers. This paper is organized as follows. Section II presents the material and method used in this research. In section III, the experiment result is discussed. Finally, the conclusion is in section IV.

\section{MATERIALS AND METHOD}

\subsection{Pico Hydropower System}

A pico hydropower plant is a power plant that is classified as a small-scale power plant that produces less than $5 \mathrm{~kW}$ of electrical energy [26]. Pico-scale hydroelectric power plants, in principle, utilize the difference in height and the amount of water discharge per second that exists in the flow of water from irrigation canals, rivers, or waterfalls. This water flow will rotate the turbine shaft to produce mechanical energy. This energy then drives the generator to produce electricity [27].

Hydroelectric power is a form of power change from hydropower with a certain height and flows into electric power, using a water turbine and a generator. Therefore, the power generated is dependent on the high and flowrate of the water [28][29]. The illustration of a pico hydropower plant is shown in Fig. 1. The power resulting can be calculated based on (1) [30].

$$
P=\rho g h Q
$$

Where $P$ is power from water kinetic energy (HP), $\rho$ is water density $\left(\mathrm{kg} / \mathrm{m}^{3}\right), g$ is the gravitational acceleration $\left(9.8 \mathrm{~m} / \mathrm{s}^{2}\right), h$ is the effective height $(\mathrm{m})$, and $Q$ is the water flow rate $\left(\mathrm{m}^{3} / \mathrm{s}\right)$.

\subsection{Generator}

Generator Set or Genset is a device that functions to generate electrical power. Referred to as a generator set with the understanding is a set of equipment combined from two different devices, namely the engine and generator or alternator. The engine is usually a diesel engine as a rotating device, while a generator or alternator is a power generating device. The engine can be a diesel engine set with diesel or gasoline, while the generator or alternator is a copper coil or coil consisting of a stator (static coil) and a rotor (rotating coil).

The proposed ELC test was carried out using a mini generator due to the location of the pico hydropower plant, which is located in a remote area. The specifications of the generator used are shown in Fig. 2, which is a single-phase AC generator with a maximum power of 650VA.

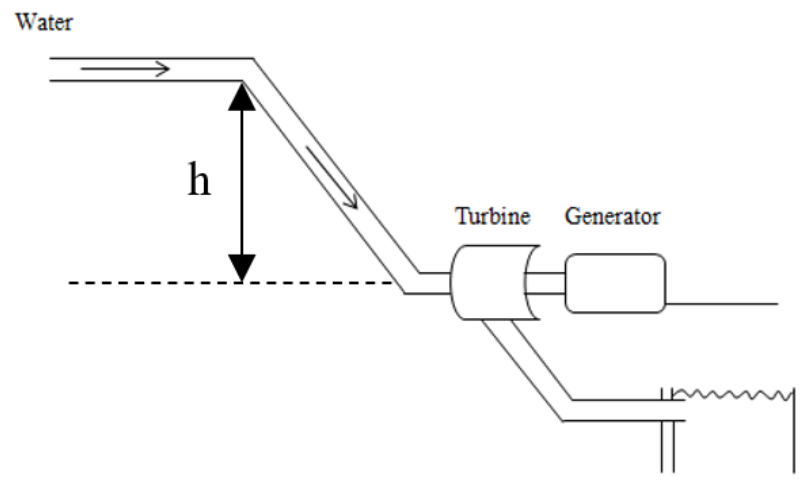

Fig. 1. Pico Hydropower Plant

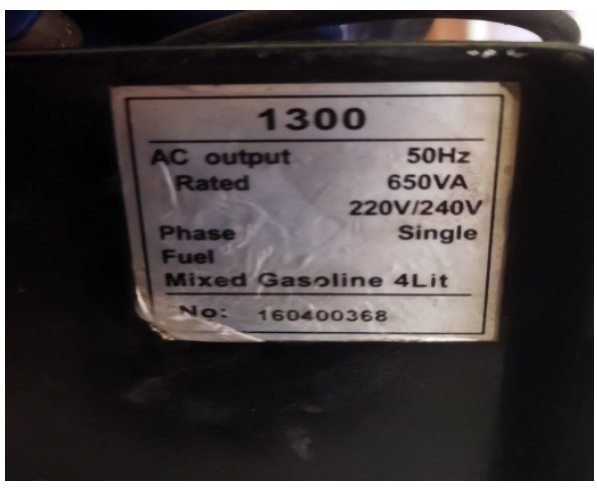

Fig. 2. Genset Specification 


\subsection{Electronic Load Controller (ELC)}

Electronic Load Controller (ELC) is a device used as LFC in a Pico-Hydropower Plant (PHP). If the power generated is more than the total consumer load demand, frequency increases and vice versa [31]. The ELC functions as a distributor of unused power by consumers, transferred to complementary loads so that $P m$ $($ Generator Power $)=P e($ Consumer Power and Complementary Power). Thus the rotation of the generator will also be constant so that the voltage changes that occur are not significant or are still within tolerance limits. The control block diagram of an ELC is shown in Fig. 3. The turbine is rotated by the water kinetic energy, which then turns the generator. Electrical power from the generator is sent to ELC, which controls the power distribution between consumer and complement load.

The ELC maintains the output power of the generator. Changes in the rotation (frequency) of the generator can be caused by changes in driving power. If the power of water entering the turbine is kept constant so that the driving force of the turbine is always constant, then the frequency and response of the generator will be a function of the load. Hence the frequency produced by the generator is always constant. The load from the generator must always be constant. For this reason, an artificial load is needed whose load can be adjusted according to the reduction of the load. This artificial load is called the complement load or dummy load. At a certain load condition (e.g., at a load of $75 \%$ full load), the power of the water entering the turbine is regulated so that the desired generator rotation is obtained. If at the consumer load there is a decrease in load by $\triangle P$, then the complement load will be passed by the current, which on average will be equal to the decrease in current due to a decrease in consumer load $(\Delta P)$. Thus the generator will be loaded with a constant total load.

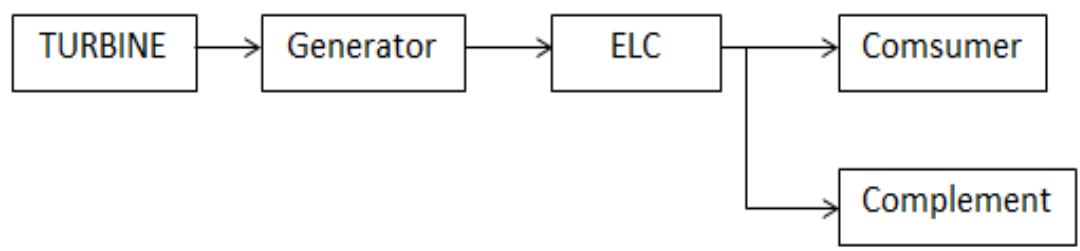

Fig. 3. Block diagram of ELC system

\subsection{Zero-Crossing Detector}

This method serves to determine the frequency of a wave by detecting the number of zero points in a time range. The zero-crossing detector is a circuit that functions to detect the intersection of the sine wave at the AC voltage with the zero point so that it can provide a reference signal when the TRIAC starts. By using a zerocrossing detector, it can detect the zero point as well as convert a sinusoidal signal (sine wave) into a square wave. The intersection of the zero points detected is at the time of the transition from the positive cycle to the negative cycle and the transition from the negative cycle to the positive cycle, illustrated by Fig. 4. The negative side of the sinus wave is inverted; hence no negative part. When the wave value is zero, the zero-crossing detector is activated by giving a high signal.

TRIAC stands for Triode Alternating Current, which means it is a triode switch for alternating current. TRIAC is a development of its predecessor, namely Diode Alternating Current (DIAC) and Silicon Control Rectifier (SCR). All three are sub-types of thyristors, silicon-based devices that are commonly used as electronic switches, in addition to transistors and Field Effect Transistors (FETs). The difference between the three is in the combination of the constituent elements, as well as in the direction of the conduction of electric current through them. TRIAC is actually a combination of two SCRs or Thyristors that are designed antiparallel with one gate electrode that is fused.

The TRIAC has the same switching characteristics as the SCR, except that the TRIAC can conduct in multiple directions. TRIAC can be used to control the flow of current in an AC circuit by adjusting the firing angle of TRIAC. The illustration of the TRIAC output waveform is shown in Fig. 5, where $\alpha$ is the firing angle or firing delay, which delays the TRIAC output wave. At the same time, thyristors work by adjusting the angle of ignition as needed so that the output voltage can vary. The setting of the thyristor ignition angle for the AC source uses the network voltage as a reference, which is detected by the zero-crossing detector because the thyristor blackout technique for the $\mathrm{AC}$ source is network commutation or also known as a natural blackout technique, namely the thyristor will turn off when it is in a reverse-biased state, where the performance depends on the zero-crossing operation of the source voltage. With the zero-crossing operation, the timing of the thyristor ignition can be set. 


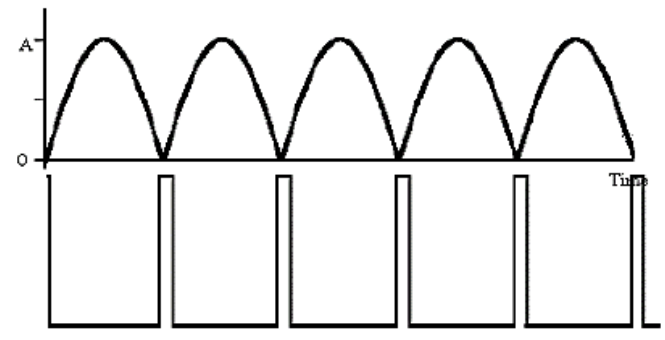

Fig. 4. Zero-Crossing Detector Output

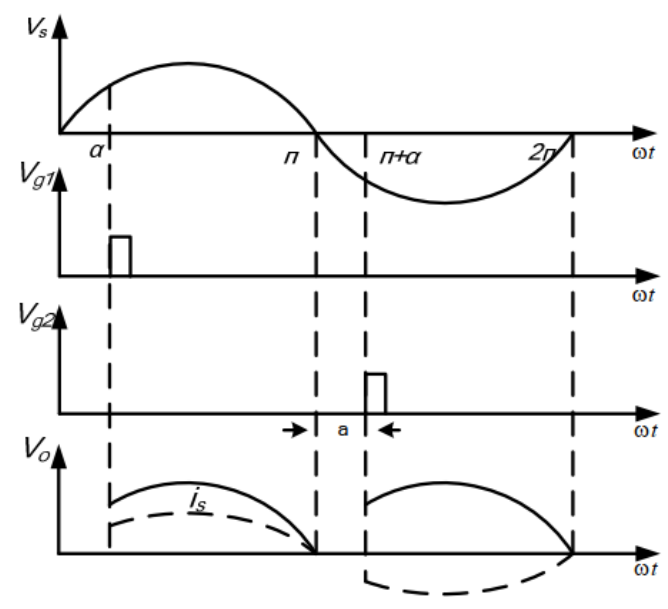

Fig. 5. TRIAC output waveform [32]

\subsection{System Design}

The ELC design consists of two stages that can be done simultaneously, namely software and hardware. Software design is the creation of a program to run the ELC. The design of the software begins with the algorithm, which reads the frequency from the output of the Zero-Crossing Detector. The targeted frequency is $50 \mathrm{~Hz}$, if the read frequency is less than $50 \mathrm{~Hz}$, the microcontroller will increase the firing delay on the TRIAC so that the power output to the dummy load will decrease, and if the read frequency is greater than 50 $\mathrm{Hz}$, the microcontroller will reduce the firing delay on the TRIAC; hence, that the power output to the dummy load will increase. Hardware design is the prototyping of Electronic Load Controllers. The design begins by making a circuit diagram of the system, as shown in Fig. 6. The Genset is used to replace the pico hydropower in laboratory testing. Zero crossing detector to detect system frequency. Arduino Uno was the main control of TRIAC and sent the data to the PC. TRIAC is used as a gating to send the excess power to the complement load. There are lamps as consumer load and a heater as complement load.

The ELC system uses a zero-crossing detector circuit to find the zero intersection of the sinusoidal signal. The Zero Crossing Detector circuit consists of a diode bridge, a filter, and an optocoupler circuit. The filter circuit is a low pass filter circuit that is used to remove noise from the generator output before entering the zero-crossing detector circuit. The optocoupler circuit uses IC 4N25 to convert the output signal from the diode bridge into a square signal so that it can be read by the microcontroller. It also detects the zero-crossing part of the signal. The zero-crossing detector is shown in Fig. 7.

The filter circuit uses resistor and capacitor components. The resistor used is $1 \mathrm{~K} \Omega$, and the capacitor is $0.1 \mathrm{uF}$. The value of the resistor and capacitor can be calculated as (2).

$$
\begin{gathered}
f=\frac{1}{2 \pi R C} \\
f=\frac{1}{2 * 3.14 * 1000 * 0.0000001} \\
f=1.592 \mathrm{~Hz}
\end{gathered}
$$

From the calculation of the low pass filter, it can be seen that the frequency value obtained is $1,592 \mathrm{~Hz}$. Therefore, a frequency greater than $1.592 \mathrm{~Hz}$ will be blocked. TRIAC driver circuit, Fig. 8, consists of an optoisolator MOC3032M which is used as a separator between the microcontroller and the high voltage generator. TRIAC BTA12 is used to control the incoming power to the dummy load by adjusting the firing delay.

The control method used is PID to stabilize the output frequency where the set-point input is $50 \mathrm{~Hz}$. The PID parameters tuning is done by trial. The frequency measurement from the zero-crossing detector is used as feedback. The output of PID is the firing delay of TRIAC, which is sent to the TRIAC driver and controls the TRIAC activation. 


\section{RESULTS AND DISCUSSION}

The laboratory testing is done to test the proposed ELC. The consumer load consists of 3 lamps arranged in parallel, each of $100 \mathrm{~W}$ and directly connected to the generator output. Whereas the complement load is a $350 \mathrm{~W}$ water heater. The design of the ELC system begins with creating a circuit schematic using EAGLE software and then printing the circuit path to the PCB. The printed PCB will be drilled for the components to be installed, then soldered. The schematic of the proposed ELC is shown in Fig. 9. There is four main part which is: (1) I/O port, (2) Zero Crossing Detector, (3) TRIAC and its driver, (4) Arduino Uno. The hardware implementation is shown in Fig. 10 where the number (1) is a terminal block, (2) is a transformer, (3) is Arduino UNO, (4) is capacitor, (5) is Diode, (6) is Optocoupler 2N25, (7) is Optocoupler MOC323, (8) is TRIAC BTA12, (9) Consumer load, (10) socket for complement load. The transformer is used to step down the voltage before entering the Zero Crossing Detector.

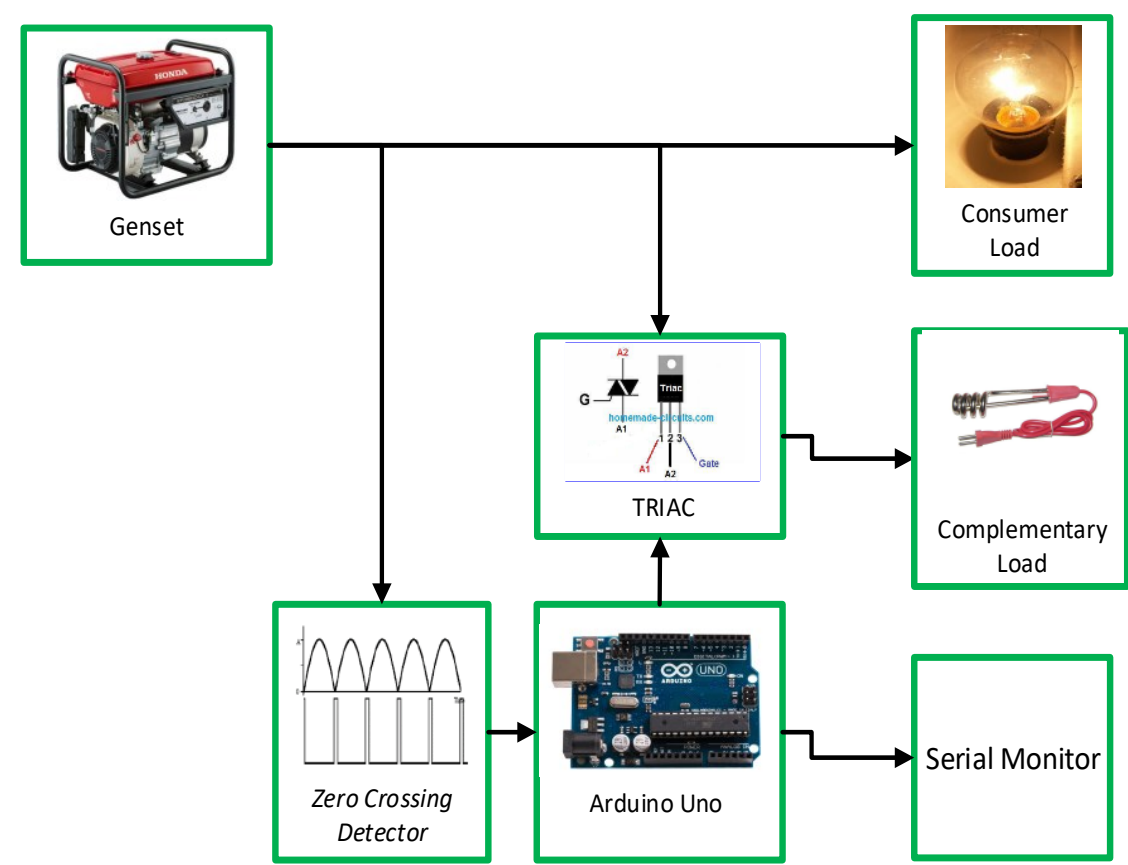

Fig. 6. System block diagram

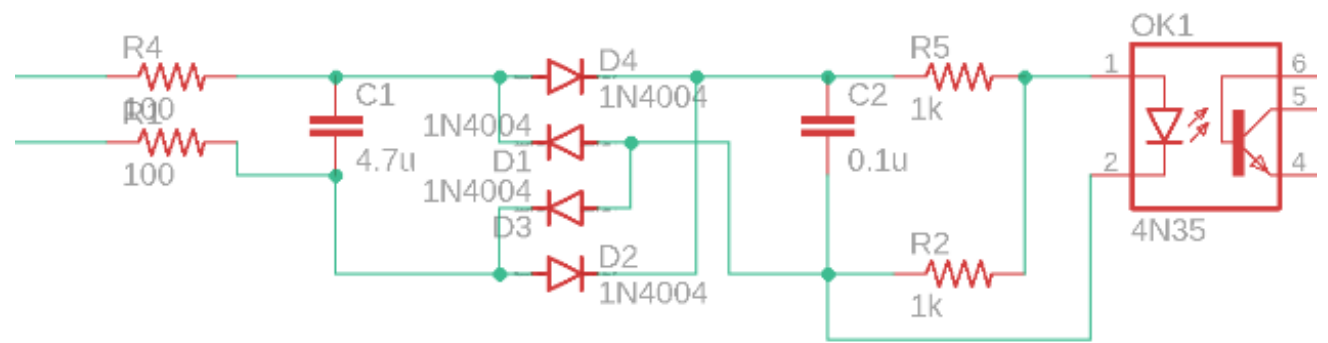

Fig. 7. Zero Crossing Detector schematic

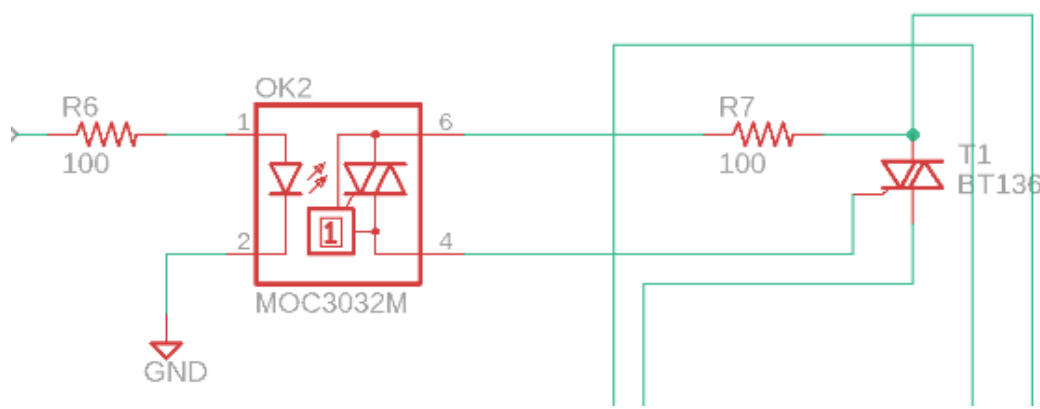

Fig. 8. TRIAC Driver 


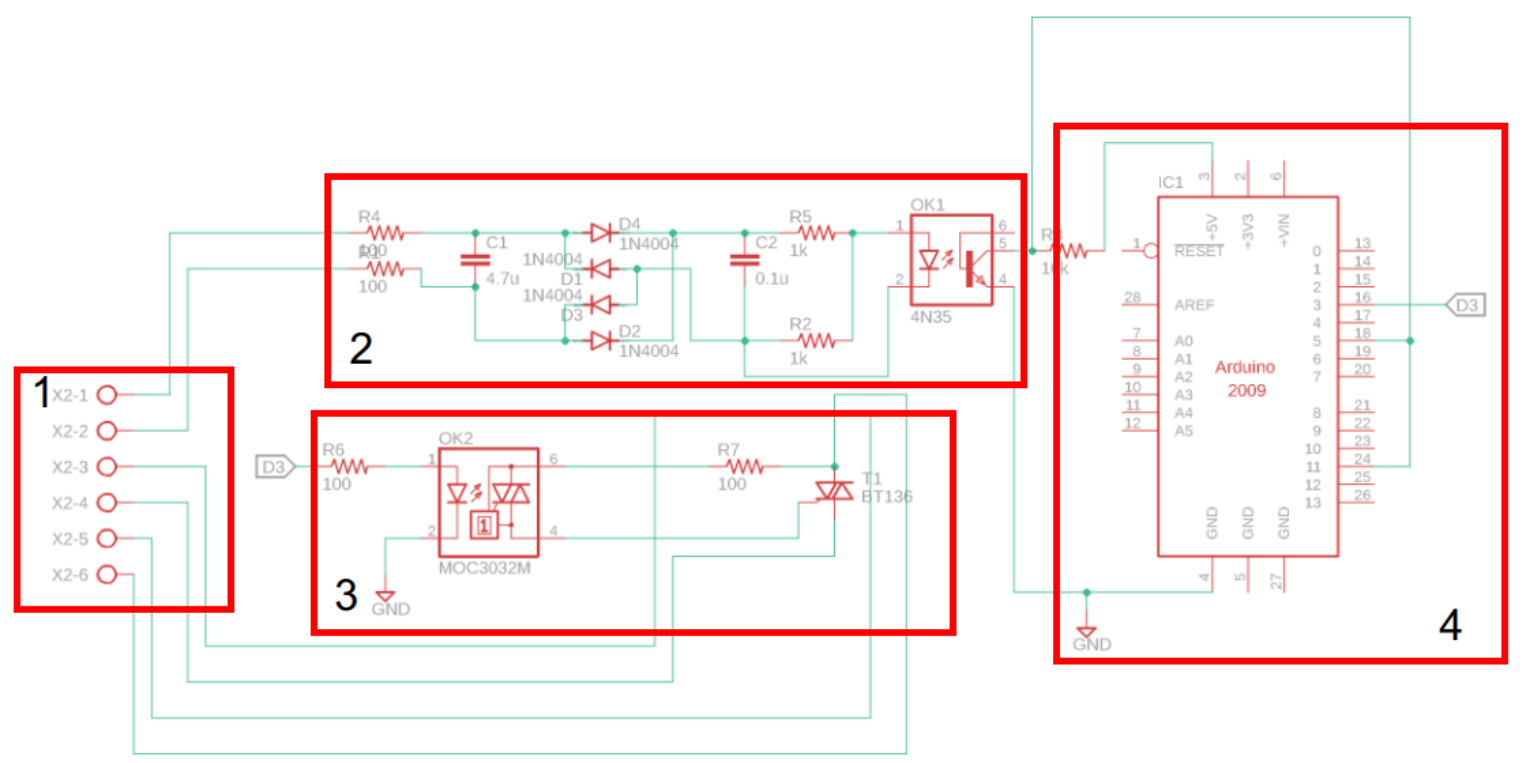

Fig. 9. Proposed ELC Schematic

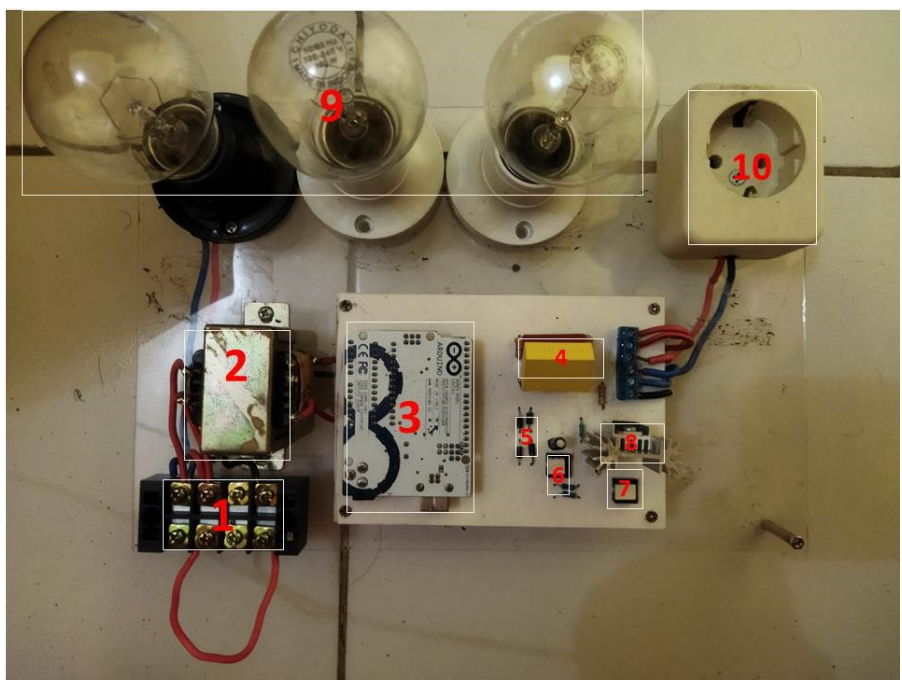

Fig. 10. Hardware testing of the proposed ELC

\subsection{Sensor Testing}

Zero crossing detector testing is done by providing an input signal from the generator and seeing the zerocrossing reading output. This test is carried out to find out that the circuit is running well for use in the Electronic Load Controller system. Fig. 11 shows the zero-crossing detector without and with a low pass filter. Without a filter, the sensor output is very noisy, which makes the reading not accurate. After using the low pass filter, the sensor reading is very clear. Since the diode bridge is used, the output waveform is all positive since the negative part is inverted. The valley of the wave means the zero-crossing part; therefore, it is used to calculate the frequency.

Sensor testing aims to determine whether the sensor readings are in accordance with the actual measuring instrument. The difference in sensor readings is used to recalibrate the sensor. Testing the level of accuracy and precision is carried out to find out how much error is contained in the sensor. The level of accuracy is represented by the value of the root mean square error (RMSE). The smaller the RMSE value, the better the level of accuracy. The sensor precision level test is represented by the mean relative standard deviation (MRSD). The smaller the coefficient value, the better the level of precision. 


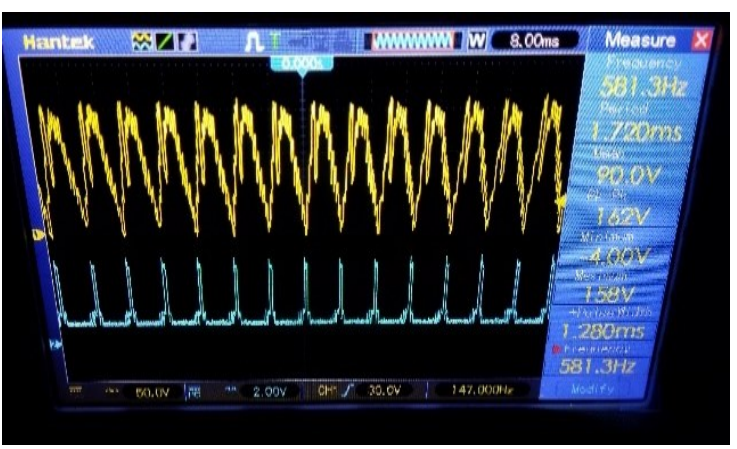

(a)Without filter

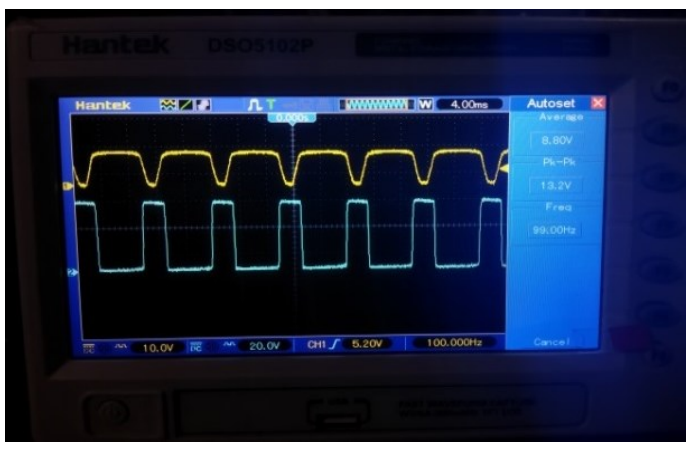

(b)Using low pass filter

Fig. 11. Output Zero Crossing Detector

The accuracy testing of the frequency sensor is done by experiment with repeated frequency readings. The experimental data were compared with the results of the frequency reading on the oscilloscope to find the root mean square error (RMSE) value. A small RMSE value indicates a better level of accuracy. From Table 1 , it can be seen that the frequency sensor readings using a zero-crossing detector have a low error with an RMSE value of $0.22 \%$ with a sensor reading accuracy of $99.78 \%$. Whereas the precision testing result is listed in Table 2, it shows that the precision of the frequency sensor is $99.99 \%$.

Table 1. Accuracy Testing of Frequency Sensor

\begin{tabular}{cccc}
\hline No. & $\begin{array}{c}\text { Oscilloscope } \\
\text { Frequency (Hz) }\end{array}$ & $\begin{array}{c}\text { Sensor } \\
\text { Frequency } \\
(\mathbf{H z})\end{array}$ & $\begin{array}{c}\text { Error } \\
\mathbf{( \% )}\end{array}$ \\
\hline 1 & 50.1 & 50 & 0.1 \\
2 & 50 & 50 & 0 \\
3 & 50 & 50 & 0 \\
4 & 50 & 50 & 0 \\
5 & 49.9 & 50 & 0.1 \\
6 & 49.9 & 50 & 0.1 \\
7 & 49.8 & 49 & 0.8 \\
8 & 49.8 & 50 & 0.2 \\
9 & 50 & 50 & 0 \\
10 & 49.9 & 50 & 0.1 \\
11 & 50.1 & 51 & 0.9 \\
12 & 50 & 50 & 0 \\
13 & 49.9 & 50 & 0.1 \\
14 & 49.9 & 50 & 0.1 \\
15 & 49.7 & 49 & 0.7 \\
\hline \multicolumn{4}{c}{ Error } \\
\hline \multicolumn{4}{c}{ Accuracy } \\
\hline
\end{tabular}

Table 2. Precision Testing of Frequency Sensor

\begin{tabular}{cc}
\hline No. & $\begin{array}{c}\text { Sensor } \\
\text { Frequency (Hz) }\end{array}$ \\
\hline 1 & 50 \\
2 & 50 \\
3 & 50 \\
4 & 50 \\
5 & 50 \\
6 & 50 \\
7 & 49 \\
8 & 50 \\
9 & 50 \\
10 & 50 \\
11 & 51 \\
12 & 50 \\
13 & 50 \\
14 & 50 \\
15 & 49 \\
\hline Standard Deviation & $\mathbf{0 . 4 6}$ \\
\hline Mean & $\mathbf{4 9 . 9 3}$ \\
\hline RSD & $\mathbf{0 . 0 0 0 0 9 1 6 6 9 8}$ \\
\hline Precision & $\mathbf{9 9 . 9 9}$ \\
\hline
\end{tabular}

\subsection{No ELC}

No ELC testing is done to know the Genset characteristic without ELC. The test is done without and with the load. The no-load test result is shown in Fig. 12. It shows that the relation between voltage and frequency output is linear. Even the Genset specification is $220 \mathrm{~V} 50 \mathrm{~Hz}$ when the voltage is $220 \mathrm{~V}$. The frequency is $55 \mathrm{~Hz}$. Whereas when the frequency $51 \mathrm{~Hz}$, the voltage output is only $120 \mathrm{~V}$. This shows that the old Genset used in this test is not in the best performance.

The loading characteristic without ELC is done by giving a $300 \mathrm{~W}$ load to the Genset step by step. The result is shown in Fig. 13. It is seen that when the load of $100 \mathrm{~W}$ is added, the voltage drops to $135 \mathrm{~V}$ with a frequency $50 \mathrm{~Hz}$. When the load becomes $200 \mathrm{~W}$, the voltage output is $118 \mathrm{~V}$ with a frequency $47 \mathrm{~Hz}$. The last load, $300 \mathrm{~W}$, the output voltage is $106 \mathrm{~V}$ with $45 \mathrm{~Hz}$. It means without ELC, the voltage and frequency drop are very high. 


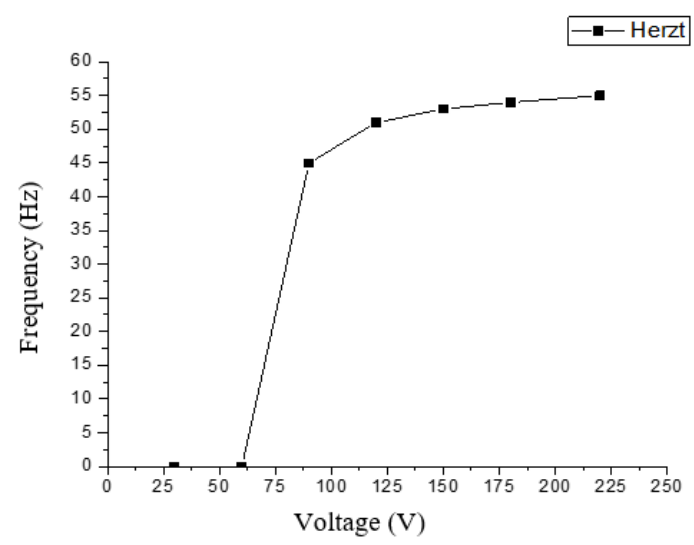

Fig. 12. No load genset output

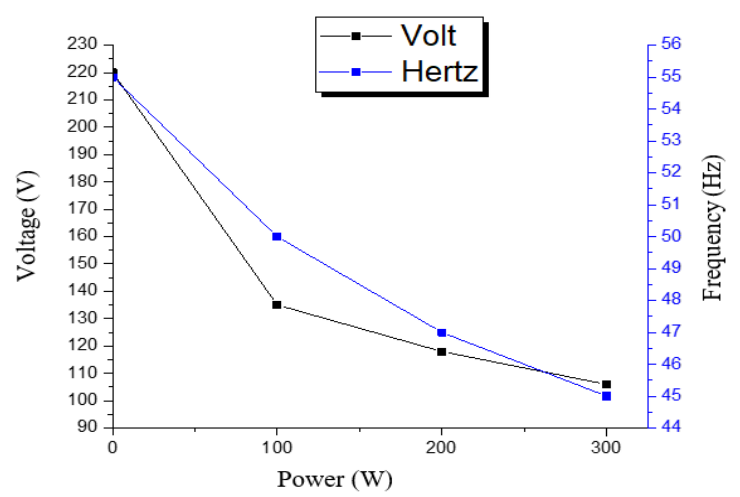

Fig. 13. Genset loaded without ELC

\subsection{Using ELC}

The ELC test is carried out by giving the load of 3 lamps with a total power of 300 Watts and then increasing the gas lever on the generator so that it reaches a voltage of $220 \mathrm{~V}$ with a frequency of $53 \mathrm{~Hz}$. Testing is done by two methods. The first method is carried out by increasing the total load and the second method is by decreasing the load.

The method of increasing the load is done by several tests. The first test is by turning on the Genset and turning off all lamp loads so that it is in a no-load condition. The second test is to turn on 1 lamp of $100 \mathrm{~W}$ and then record the response in stabilizing the output frequency on the generator. The third test is to turn on 2 lights so that the power used becomes $200 \mathrm{~W}$. The fourth test is by turning on 3 lights so that the power used becomes $300 \mathrm{~W}$ then recording the response in stabilizing the frequency.

The result of the increasing load test is listed in Table 3. After the Genset is activated during the no-load condition, the frequency immediately drops from the previous $53 \mathrm{~Hz}$ to $50 \mathrm{~Hz}$. The frequency that drops and is constant at $50 \mathrm{~Hz}$ indicates that the system, including ELC, is working properly. The voltage that was $220 \mathrm{~V}$ dropped to $186 \mathrm{~V}$ due to the reduced rpm of the generator engine, which follows the frequency reduction. The voltage drop is also due to the low efficiency of the generator, as seen in the no-load generator test, where at a voltage of $220 \mathrm{~V}$, the output frequency is $55 \mathrm{~Hz}$. Tests with 1 lamp, 2 lamps, and 3 lamps also performed well at a stable output frequency of $50 \mathrm{~Hz}$ and stable voltage, which is $183 \pm 1 \mathrm{~V}$. The addition of the load affects the delay given to the TRIAC. The greater the value of the power used, the greater the delay. The output on the dummy load will decrease as the power used in the main load increases. Fig. 14 shows the output frequency of the system and the corresponding firing delay of the TRIAC. When the load is increasing, the firing delay is also increased, which means a smaller TRIAC opening to the dummy load. There are many fluctuations in the graph which means the system maintains the output frequency at $50 \mathrm{~Hz}$.

The load reduction method is carried out by several tests. The first test is to turn on the Genset and turn on all the lamps so that the total load used is $300 \mathrm{~W}$. The second test is to turn off 1 lamp so that the main load becomes 2 lamps worth $200 \mathrm{~W}$, then record the response. The third test is to turn off 1 more lamp so that the power used becomes $100 \mathrm{~W}$ and then record the response of the ELC in stabilizing the frequency. The fourth test is to turn off all lights so that no load is used and then record the response in stabilizing the frequency.

In Table 4, it can be seen that the test starts at a load of 3 lamps of $300 \mathrm{~W}$. The constant output frequency at $50 \mathrm{~Hz}$ indicates that the device is working properly. Tests with 2 lamps, 1 lamp, and without lamps also worked well at a stable output frequency of $50 \mathrm{~Hz}$. The decrease in load affects the delay given to the TRIAC. The smaller the power value used, the smaller the delay. The output on the dummy load will increase as the power used in the main load decreases. Whereas Fig. 15 shows the TRIAC switching condition. It is inverse from Fig. 14. Decreasing the number of loads makes the firing delay decreases which means more power is sent to the dummy load.

Table 3. Increasing Load Testing

\begin{tabular}{cccccccc}
\hline \multirow{2}{*}{ Load } & \multicolumn{4}{c}{ Generator Output } & \multicolumn{3}{c}{ Dummy Load } \\
\cline { 2 - 8 } & $\mathrm{V}(\mathrm{v})$ & $\mathrm{I}(\mathrm{A})$ & $\mathrm{P}(\mathrm{W})$ & Freq $(\mathrm{Hz})$ & $\mathrm{V}(\mathrm{v})$ & $\mathrm{I}(\mathrm{A})$ & $\mathrm{P}(\mathrm{W})$ \\
\hline No load & 186 & 0 & 0 & 50 & 132 & 1.6 & 211.2 \\
100W & 183 & 0.2 & 36.6 & 50 & 99 & 1.4 & 138.6 \\
200W & 184 & 0.8 & 147.2 & 50 & 65 & 1 & 65 \\
300W & 182 & 1.3 & 236.6 & 50 & 41.5 & 0.7 & 29.05 \\
\hline
\end{tabular}



Vol. 7, No. 3, December 2021, pp. 461-471

Table 4. Decreasing Load Testing

\begin{tabular}{cccccccc}
\hline \multirow{2}{*}{ Load } & \multicolumn{4}{c}{ Generator Output } & \multicolumn{3}{c}{ Dummy Load } \\
\cline { 2 - 8 } & $\mathrm{V}(\mathrm{v})$ & $\mathrm{I}(\mathrm{A})$ & $\mathrm{P}(\mathrm{W})$ & Freq $(\mathrm{Hz})$ & $\mathrm{V}(\mathrm{v})$ & $\mathrm{I}(\mathrm{A})$ & $\mathrm{P}(\mathrm{W})$ \\
\hline 300W & 182 & 1.3 & 236.6 & 50 & 41.5 & 0.7 & 29.05 \\
200W & 182.1 & 0.8 & 145.68 & 50 & 69.3 & 1 & 69.3 \\
100W & 180.3 & 0.2 & 36.06 & 50 & 101 & 1.5 & 151.5 \\
No load & 187 & 0 & 0 & 50 & 132.6 & 1.6 & 212.16 \\
\hline
\end{tabular}

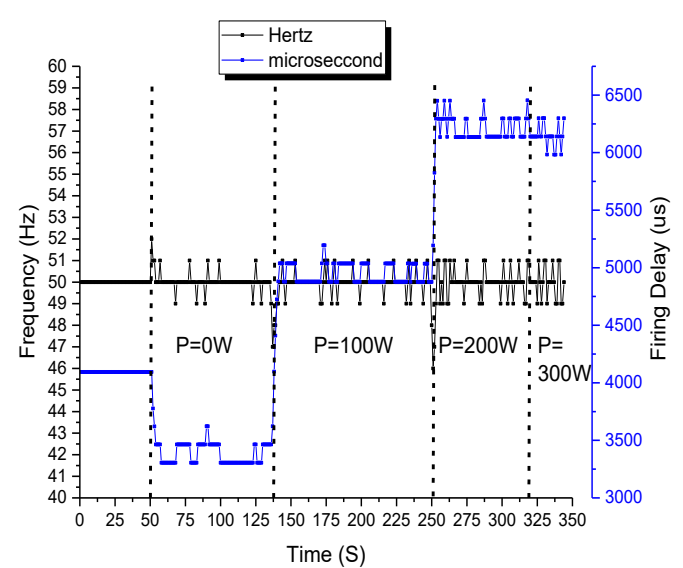

Fig. 14. ELC increasing load test

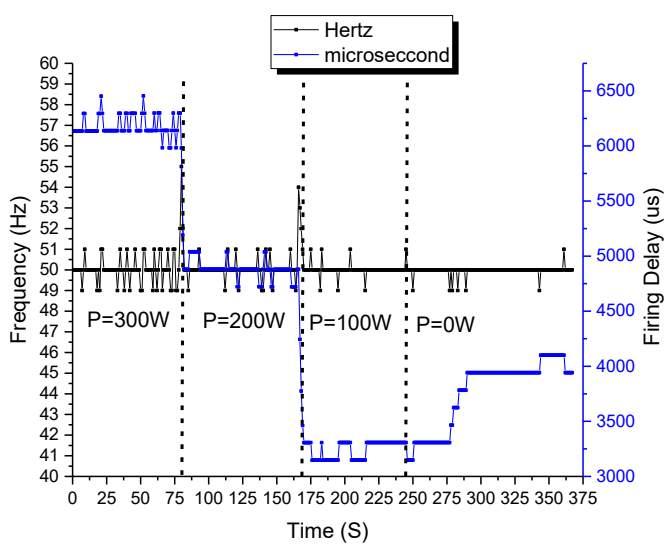

Fig. 15. ELC decreasing load test

\section{CONCLUSION}

The design and prototype of the ELC for the Pico Hydropower Plant(PHP) are already done and tested on the laboratory scale. The main part of ELC is the frequency sensor and gating system. The first part is made by a Zero Crossing Detector, which detects the generator frequency. The gating system developed with TRIAC has the function to distribute the power to the consumer and complement load based on the frequency condition. The results of the frequency sensor accuracy test are $99.78 \%$, and the precision is $99.99 \%$. The ELC system can adjust the frequency automatically by setting the firing delay on the TRIAC to distribute unused power by consumer loads to complementary loads so that the load used remains stable. The ELC is tested with increasing and decreasing load. The proposed ELC gives a stable frequency at $50 \mathrm{~Hz}$. Whereas at the first test, the mean voltage is $183 \mathrm{~V}$, and in the second test is $182.17 \mathrm{~V}$. The low output voltage is due to the low efficiency of the generator, as seen in the no-load generator test, where at $220 \mathrm{~V}$, the output frequency is $55 \mathrm{~Hz}$.

\section{Acknowledgments}

This research is the collaboration between Universitas Sultan Ageng Tirtayasa (UNTIRTA) and Universitas Sebelas Maret (UNS).

\section{REFERENCES}

[1] K. Gaiser, P. Erickson, P. Stroeve, and J. P. Delplanque, "An experimental investigation of design parameters for pico-hydro Turgo turbines using a response surface methodology," Renewable Energy, vol. 85, pp. 406-418, 2016. https://doi.org/10.1016/j.renene.2015.06.049

[2] S. J. Williamson, B. H. Stark, and J. D. Booker. "Performance of a low-head pico-hydro Turgo turbine," Applied Energy, vol. 102, pp. 1114-1126, 2013. https://doi.org/10.1016/j.apenergy.2012.06.029

[3] J.A. Laghari, H. Mokhlis, A. H. A. Bakar, and H. Mohammad, "A comprehensive overview of new designs in the hydraulic, electrical equipments and controllers of mini hydro power plants making it cost effective technology," Renewable and sustainable Energy reviews, vol. 20, pp. 2013. https://doi.org/10.1016/j.rser.2012.12.002

[4] K. Sopian, and J. AB. Razak. "Pico hydro: clean power from small streams," In Proceedings of the 3rd world scientific and engineering academy and society international conference on renewable energy sources, pp. 414-419, 2009. http://www.wseas.us/e-library/conferences/2009/lalaguna/EPREWA/EPREWA64.pdf

[5] P. Bhusal, A. Zahnd, M. Eloholma, and L. Halonen, "Energy efficient innovative lighting and energy supply solutions in developing countries," International Review of Electrical Engineering, vol. 2, no. 5, pp. 665-670, 2007. https://core.ac.uk/download/pdf/11243092.pdf 
[6] M. F. Basar, A. Ahmad, N. Hasim, and K. Sopian, "Introduction to the pico hydro power and the status of implementation in Malaysia," In 2011 IEEE Student Conference on Research and Development, pp. 283-288. IEEE, 2011. https://doi.org/10.1109/SCOReD.2011.6148751

[7] A. M. A. Haidar, M. F. M. Senan, A. Noman, and T. Radman, "Utilization of pico hydro generation in domestic and commercial loads," Renewable and Sustainable energy reviews, vol. 16, no. 1, pp. 518-524, 2012. https://doi.org/10.1016/j.rser.2011.08.017

[8] T. Meier and G. Fischer, "Assessment of the Pico and Micro-hydropower Market in Rwanda," Nairobi (Kenya): GVEP, 2011. https://energy4impact.org/sites/default/files/pico-hydro market in rwanda.pdf

[9] Y. Xu, C. Li, Z. Wang, N. Zhang, and B. Peng, "Load frequency control of a novel renewable energy integrated micro-grid containing pumped hydropower energy storage," IEEE Access, vol. 6 pp. 29067-29077, 2018. https://doi.org/10.1109/ACCESS.2018.2826015

[10] D. Guha, P.K. Roy, and S. Banerjee, "Quasi-oppositional differential search algorithm applied to load frequency control," Engineering Science and Technology, an International Journal, vol. 19, no. 4, pp. 1635-1654, 2016. https://doi.org/10.1016/j.jestch.2016.09.021

[11] H. Bevrani, F. Habibi, P. Babahajyani, M. Watanabe, and Y. Mitani, "Intelligent frequency control in an AC microgrid: Online PSO-based fuzzy tuning approach," IEEE transactions on smart grid, vol. 3, no. 4, pp. 1935-1944, 2012. https://doi.org/10.1109/TSG.2012.2196806

[12] J. Yang, Z. Zeng, Y. Tang, J. Yan, H. He, and Y. Wu, "Load frequency control in isolated micro-grids with electrical vehicles based on multivariable generalized predictive theory," Energies, vol. 8, no. 3, pp. 2145-2164, 2015. https://doi.org/10.3390/en8032145

[13] Woei-Luen Chen and Yuan-Yih Hsu, "Experimental Evaluation of an Isolated Induction Generator with Voltage and Frequency Control," International Symposium on Power Electronic, Electrical Drives, Automation and Motion, pp. 497-502, 2006. https://doi.org/10.1109/SPEEDAM.2006.1649823

[14] N. W. Aug dan A. Z. Ya, "Microkontroller Based Electrical Parameter Monitoring System of Electronic Load Controller Used in Micro Hydro Power Plant," Jurnal of Electrical and Engineering, vol. 3, no. 5, pp. 97-109, 2015. https://doi.org/10.11648/j.jeee.20150305.11

[15] H. H. Alhelou, M. E. H. Golshan, R. Zamani, E. H. Forushani, and P. Siano, "Challenges and opportunities of load frequency control in conventional, modern and future smart power systems: a comprehensive review." Energies 11, no. 10, 2018. https://doi.org/10.3390/en11102497

[16] A. T. Hammid, M. Hojabri, M. H. Sulaiman, A. N. Abdalla, and A. A. Kadhim, "Load frequency control for hydropower plants using pid controller," Journal of Telecommunication, Electronic and Computer Engineering (JTEC), vol. 8, no. 10, pp. 47-51, 2016. https://jtec.utem.edu.my/jtec/article/view/1370

[17] R. Thirunavukarasu and I. A. Chidambaram, "PI2 controller based coordinated control with Redox Flow Battery and Unified Power Flow Controller for improved Restoration Indices in a deregulated power system," Ain Shams Engineering Journal, vol. 7, no. 4, pp. 1011-1027, 2016. https://doi.org/10.1016/j.asej.2015.08.001

[18] Y. Zheng, J. Zhou, Y. Xu, Y. Zhang, and Z. Qian, "A distributed model predictive control based load frequency control scheme for multi-area interconnected power system using discrete-time Laguerre functions," ISA transactions, vol. 68, pp. 127-140, 2017. https://doi.org/10.1016/j.isatra.2017.03.009

[19] H. Yousef, "Adaptive fuzzy logic load frequency control of multi-area power system," International Journal of Electrical Power \& Energy Systems, vol. 68 pp. 384-395, 2015. https://doi.org/10.1016/j.ijepes.2014.12.074

[20] C. Li,, Y. Mao, J. Zhou, N. Zhang, and X. An, "Design of a fuzzy-PID controller for a nonlinear hydraulic turbine governing system by using a novel gravitational search algorithm based on Cauchy mutation and mass weighting," Applied Soft Computing, vol. 52, pp. 290-305, 2017. https://doi.org/10.1016/j.asoc.2016.10.035

[21] S. Prakash, and S. K. Sinha. "Simulation based neuro-fuzzy hybrid intelligent PI control approach in four-area load frequency control of interconnected power system," Applied Soft Computing, vol. 23, pp. 152-164, 2014. https://doi.org/10.1016/j.asoc.2014.05.020

[22] F. Daneshfar and H. Bevrani, "Multiobjective design of load frequency control using genetic algorithms," International Journal of Electrical Power \& Energy Systems, vol. 42, no. 1, pp. 257-263, 2012. https://doi.org/10.1016/j.ijepes.2012.04.024

[23] S.S. Dhillon, J.S. Lather, and S. Marwaha, "Multi area load frequency control using particle swarm optimization and fuzzy rules," Procedia Computer Science, vol. 57, pp. 460-472, 2015. https://doi.org/10.1016/j.procs.2015.07.363

[24] N.H. Saad, A.A. El-Sattar, and AEAM. Mansour, "A novel control strategy for grid connected hybrid renewable energy systems using improved particle swarm optimization," Ain Shams Engineering Journal, vol. 9, no. 4, pp. 2195-2214, 2018. https://doi.org/10.1016/j.asej.2017.03.009

[25] R.K. Sahu, G.T.C. Sekhar, and S. Panda, "DE optimized fuzzy PID controller with derivative filter for LFC of multi source power system in deregulated environment," Ain Shams Engineering Journal, vol. 6, no. 2, pp. 511-530, 2015. https://doi.org/10.1016/j.asej.2014.12.009

[26] H. Zainuddin, M. S. Yahaya, J. M. Lazi, M. F. M. Basar, and Z. Ibrahim, "Design and development of pico-hydro generation system for energy storage using consuming water distributed to houses," World Academy of Science, Engineering and Technology, vol. 59, no. 1, pp. 154-159, 2009. https://doi.org/10.1109/ICDRET.2009.5454216

[27] R. K. Saket, "Design aspects and probabilistic approach for generation reliability evaluation of MWW based microhydro power plant," Renewable and Sustainable Energy Reviews, vol. 28, pp. 917-929, 2013. https://doi.org/10.1016/j.rser.2013.08.033 
[28] A. Desai, I. Mukhopadhyay, and A. Ray. "Theoretical analysis of a Pico-hydro power system for energy generation in rural or isolated area," In 2014 IEEE PES Asia-Pacific Power and Energy Engineering Conference (APPEEC), pp. 1-4, IEEE, 2014. https://doi.org/10.1109/APPEEC.2014.7066043

[29] M.F. Basar, A. Ahmad, N. Hasim, and K. Sopian. "Introduction to the pico hydro power and the status of implementation in Malaysia," In 2011 IEEE Student Conference on Research and Development, pp. 283-288, IEEE, 2011. https://doi.org/10.1109/SCOReD.2011.6148751

[30] A. Kadier, M.S. Kalil, M. Pudukudy, H.A. Hasan, Azah Mohamed, and Aidil Abdul Hamid, "Pico hydropower (PHP) development in Malaysia: Potential, present status, barriers and future perspectives," Renewable and Sustainable Energy Reviews, vol. 81, pp. 2796-2805, 2018. https://doi.org/10.1016/j.rser.2017.06.084

[31] A. Safaei, H. M. Roodsari, and H. A. Abyaneh, "Optimal load frequency control of an island small hydropower plant," In The 3rd Conference on Thermal Power Plants, pp. 1-6, IEEE, 2011. https://ieeexplore.ieee.org/abstract/document/6576991

[32] Tarmizi, "Desain Sistem Kontrol Sudut Penyalaan ThyristorKomutasi Jaringan Berbasis Mikrokontroler PIC 16F877," Jurnal Rekayasa Elektrika, vol. 9, no. 1, 2010. http://jurnal.unsyiah.ac.id/JRE/article/view/172

\section{BIOGRAPHY OF AUTHORS}
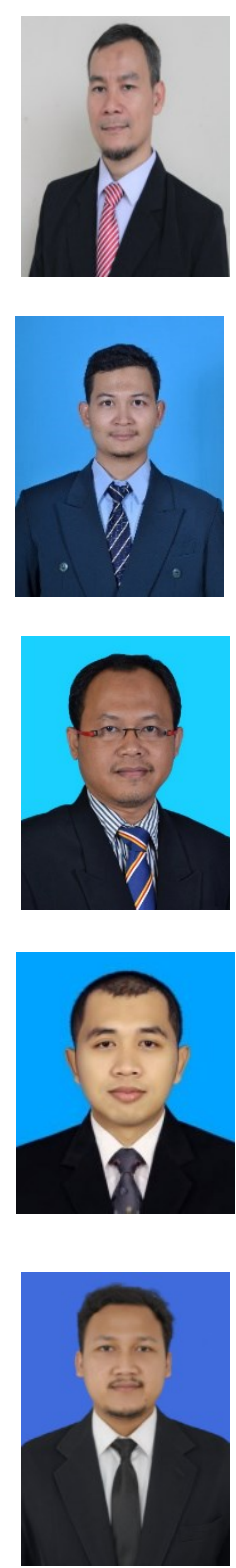

Supriyanto Praptodiyono is a member of IEEE and FORTEI. He obtained his bachelor's from the Department of Electrical Engineering, Universitas Brawijaya in 1999. His master's and doctoral's degree were from National Advanced IPv6 Centre, Universiti Sains Malaysia in 2010 and 2015. He is currently a lecturer in the Department of Electrical Engineering, Universitas Sultan Ageng Tirtayasa, Indonesia. His research interest involves network security and IPv6. Email: supriyanto@untirta.ac.id

Hari Maghfiroh obtained his bachelor's and master's degree from the Department of Electrical Engineering and Information Technology, Universitas Gadjah Mada, Indonesia in 2013 and 2014. He also joints a double degree master program at the National Taiwan University of Science and Technology in 2014. He is currently a lecturer in the Department of Electrical Engineering, Sebelas Maret University, Indonesia. His research interests involve control systems, electric vehicles, and railway systems. Email: hari.maghfiroh@staff.uns.ac.id

Muhammad Nizam is a professor at Electrical Engineering Dept., Sebelas Maret University, Indonesia. He received his Ph.D. degree from University Kebangsaan Malaysia. His research interests are in Power Systems, Power Quality, Management Energy, Energy Storage Systems, Electric Vehicles, as well as Battery Management Systems. One of his research interests is energy storage systems and its application. Email: muhammad.nizam@staff.uns.ac.id

Chico Hermanu obtained his bachelor's degree from the Department of Electrical Engineering, Institut Teknologi Sepuluh Nopember (ITS), and master's degree in the same field from the Department of Electrical Engineering and Information Technology, Universitas Gadjah Mada. He is currently a lecturer in the Department of Electrical Engineering, Sebelas Maret University, Indonesia. His research interests involve renewable energy, artificially intelligence, power electronics and control, the internet of things, and electric vehicle. Email: chico@ft.uns.ac.id

Arif Wibowo is a fresh-graduate student from the Department of Electrical Engineering, Universitas Sebelas Maret. Email: arifwibowo839@gmail.com 